\title{
O papel da leitura na (re)construção da identidade da criança migrante: o exemplo de Pássaro que voa, de Claudio Hochman'
}

\author{
The Role of Reading in the (Re)construction of the Identity of the Migrant \\ Child: Example in Pássaro que voa by Claudio Hochman
}

\author{
JULIANA GARBAYO DOS SANTOS \\ Universidad de Aveiro \\ Portugal \\ dra.juliana.garbayo@gmail.com
}

(Recibido: $14-\mathrm{O} 4-2 \mathrm{O} 2 \mathrm{O}$ aceptado: I2-II-2O2O)

Resumo. Este artigo propõe uma reflexão sobre o papel da leitura como ferramenta de resiliência e reconstrução identitária perante os desafios psíquicos suscitados pela migração. Após uma investigação qualitativa sobre a opinião de um pequeno grupo de psiquiatras infantis e psicólogos quanto à contribuição da leitura para a elaboração do luto inerente à migração, analisamos, à luz das respostas, o livro infantojuvenil Pássaro que voa. A obra foi escolhida por atender a dois critérios: ser uma publicação recente em Portugal e estar disponível na rede de bibliotecas municipais da cidade onde se deu 0 estudo - e, portanto, acessível à população local de forma gratuita e igualitária. Praticamente todos os temas que os profissionais entrevistados apontaram como relevantes para a criança migrante - como questões identitárias, respeito às diferenças, exclusão social, perdas, saudades, medos, luto e esperança - estão presentes na obra. Acreditamos que, ao abordar tópicos disruptivos e validar sentimentos de perda, saudade, medo e estranhamento, este e outros livros do gênero podem contribuir para a criação de uma sociedade mais empática e verdadeiramente intercultural.

Palavras-chave: migração; leitura; livro infantil; multiculturalismo; Pássaro que voa.
Abstract. This paper proposes a reflection on the role of reading as a tool for resilience and identity reconstruction when facing the psychological challenges raised by migration. After a qualitative investigation into the opinion of a small group of child psychiatrists and psychologists regarding the contribution of reading to the grief process inherent to migration, in the light of their responses, the children's book Pássaro que voa was analyzed. This title was chosen based on two criteria: being a recent publication in Portugal and being available in public libraries local to the area where the study took place and, therefore, being available to the regional population free of charge and in an equal manner. Almost all of the themes identified by the professionals as relevant to the migrant child - such as identity issues, respect for differences, social exclusion, losses, longing, grief, and hope - are present in this literary work. We believe that this and other similar books, by approaching disruptive topics and validating feelings of loss, fear, and unfamiliarity - may contribute to the creation of a more empathetic and truly intercultural society.

Keywords: migration; reading; children books; multiculturalism; Pássaro que voa.

\footnotetext{
${ }^{\text {I }}$ Para citar este artículo: : Garbayo dos Santos, Juliana (2O2I). O papel da leitura na (re)construção da identidade da criança migrante: o exemplo de Pássaro que voa, de Claudio Hochman. Alabe 23 [www.revistaalabe.com]

DOI: Io.I5645/Alabe2O2I.23.9
} 


\section{Introdução}

A migração é um fenômeno multifatorial que vem se tornando cada vez mais relevante nos últimos anos. O continente europeu, como destino de milhares de imigrantes e refugiados, ocupa um papel expressivo neste cenário. Entre 20I5 e início de 20I8, mais de 33 mil refugiados foram acolhidos na Europa - Portugal foi um dos países europeus que realocou mais refugiados em termos relativos (Plataforma de apoio aos refugiados, 20I8). Entre refugiados e migrantes, o país é atualmente residência oficial para 480.300 estrangeiros (Serviço de estrangeiros e fronteiras, 20I9: I6).

Muitas razões podem levar uma pessoa a deixar seu país, embora a busca por maior qualidade de vida seja, quase sempre, o fator subjacente (Agência da ONU para refugiados, 20I7). Aqueles que decidem migrar enfrentam um enorme desafio: deixar todo seu mundo conhecido para trás (o que, inevitavelmente, implica em perdas). Enquanto lidam com o luto advindo dessas perdas, precisam lutar para reencontrar seu lugar (e sua identidade) em um país onde tudo é novo. Entre aqueles que migram por razões humanitárias, fugindo de guerras, perseguições, violações dos direitos humanos e outras situações intoleráveis - os chamados refugiados - o trauma e o luto envolvidos no processo de migrar são ainda mais significativos e podem estar presentes desde muito antes da mudança.

As crianças são particularmente afetadas pela migração, especialmente a humanitária (ou forçada). Até metade dos refugiados são crianças; muitas são obrigadas a viajar sozinhas (Plataforma de apoio aos refugiados, 20I8). Apenas em 20I\%, mais de I7 mil menores desacompanhados chegaram à Europa (idem).

A migração voluntária, embora não envolva a mesma carga de trauma, também pode ser altamente estressante para as crianças, que guardam pouco controle sobre as decisões envolvidas no processo (como país de destino, momento da mudança, entre outros). Infelizmente, muitas famílias não preparam adequadamente as crianças para a experiência, podendo mesmo excluí-las completamente de todos os estágios preparatórios - em casos extremos, elas sequer são informadas sobre os planos de mudança (Candy e Butterworth, I998: 22; Valle, 2002: 6oI). Estas atitudes, obviamente, podem gerar intensa ansiedade e frustração na criança, ampliando os efeitos traumáticos de um processo já tão estressante por si só.

\section{A migração na literatura infantojuvenil}

Livros espelham as preocupações de seu tempo e a literatura infantil não foge a este princípio. Uma vez que são os adultos que compram - e escrevem - os livros que as crianças leem, é compreensível (mesmo esperado) que desejem educá-las para os temas a que são sensíveis e que julgam socialmente relevantes. Neste sentido, os livros infantojuvenis costumam representar as ansiedades culturais das sociedades em que são produzidos (Morgado, 20IO: I3). 
Como ressalta Balça (2008: 25):

os textos de literatura infantil não são inocentes, e para além de encerrarem em si mesmos valores literários e valores estéticos, estão igualmente impregnados de valores sociais e de valores éticos. A literatura infantil é assim não só um veículo de convenções literárias, mas também de paradigmas e de comportamentos vigentes e considerados adequados pela sociedade em geral.

Assim, é natural que a migração, sendo uma questão tão relevante no contexto mundial contemporâneo, esteja cada vez mais presente nos livros de recepção infantil. Em Portugal, questões relacionadas ao fenômeno, como multiculturalismo, racismo e xenofobia têm sido frequentemente abordadas nestes livros (Ramos, 20I6: 36 ).

\section{Leitura e resiliència}

Como lembra Estés (I999: I5), histórias são bálsamos medicinais e nelas estão "incrustadas instruções que nos orientam a respeito das complexidades da vida". Ao oferecer as mediações e representações simbólicas necessárias para organizar nossa confusão interna, elas permitem que analisemos os recônditos mais profundos de nós mesmos a partir de um lugar seguro. Ler sobre aquilo que aconteceu "com outra pessoa" ou "há muito tempo atrás" provê o distanciamento necessário para que ousemos iluminar e revelar os ecos - até então obscuros e confusos - daquilo que vivemos (Petit, 2009: 47). Como resume Petit (47-48):

Quando não é encarada como algo que é imposto, uma história ouvida - ou uma frase - pode muito rapidamente se tornar parte do indivíduo e, ao mesmo tempo que mantém uma distância que o protege, permite que ele rememore a sua própria história, especialmente os capítulos mais difíceis. Pois são particularmente as páginas dolorosas de nossas vidas que podem ser lidas de maneira indireta. «Fala de mim, sem que eu seja obrigada a falar de mim», como diz uma mulher à Karine Brutin, professora de literatura que acompanha jovens com grande desamparo psíquico $[\ldots]$

Sendo assim, podemos dizer que os livros são ferramentas poderosas que facilitam a elaboração psíquica e que são especialmente úteis em momentos de crise, já que, como defende Bettelheim (2002: 6), é principalmente quando a vida se torna mais 
desconcertante que a literatura ajuda a dar um sentido coerente ao turbilhão de sentimentos e mostra, de forma simbólica, como lidar com questões que afligem. Para Petit (2009: 9), isso é ainda mais verdadeiro quando as crises em questão afetam a autorrepresentação e o sentido da vida - precisamente o que ocorre na migração, onde diversos elementos que moldam o senso de self do indivíduo (família, amigos, animais de estimação, idioma, posição social, escola, emprego e pertences materiais como roupas, livros, brinquedos e comida) são deixados para trás (Valle, 2002: 600).

Mais do que reencontrar sua identidade, o migrante precisa encontrar uma nova posição para si mesmo nesta sociedade que, antes estranha, agora é a sua também. Neste sentido, Petit (200I: 42-44) afirma que a leitura permite escapar das prescrições sociais e cria um atalho para um espaço íntimo e privado no qual o jovem leitor não depende dos outros. Este “outro lugar” nada mais é do que um espaço psíquico que pode ser o mesmo lugar da elaboração ou da reconquista da posição do sujeito.

A literatura, no entanto, não pode fazer muito pelas crianças que trazem sofrimentos e sentimentos confusos a não ser que toque em pontos nevrálgicos para elas. Como Bettelheim (2002: 5) sinalizou, a literatura infantil pode divertir, entreter e despertar a curiosidade da criança, mas, para realmente enriquecer sua vida, deve ajudá-la a "tornar mais claras suas emoções, harmonizar-se com suas ansiedades e aspirações, reconhecer plenamente suas dificuldades e, ao mesmo tempo, sugerir soluções para os problemas que a perturbam".

\section{Biblioterapia}

A biblioterapia pressupõe a utilização da literatura como meio terapêutico (Pardeck, I990: IO43) partindo da premissa de que livros cuidadosamente selecionados podem ser usados para ajudar adultos e crianças a expressar sentimentos e preocupações de forma a lidar mais adaptativamente com as mudanças e dificuldades da vida (Berg, Devlin e Gedaly-Duff, ı980: 38; Lindeman e Kling, r969: 40; Lucas e Soares, 2OI3: I39).

A técnica vem sendo usada há tempos em ambientes tão diversos como hospitais psiquiátricos, consultórios de psicologia e escolas (Lindeman e Kling, I969: 40) para ajudar crianças que sofrem com transtornos ansiosos (Rapee, Abbott e Lyneham, 2006), luto (Berg et al., I980), problemas familiares (Pardeck e Markward, I995) e diversas outras condições. A biblioterapia, no entanto, não se resume à atividade de leitura. Embora o livro atue como "catalisador", o verdadeiro trabalho psíquico depende da reflexão e discussão sobre o material lido (Schlenther, I999: 3I; Webster, I96r: I6I) - e, eventualmente, engloba atividades criativas como desenho, escrita e dramatização (Lucas e Soares, 20I3: І39; Pardeck, I990: IO47).

Quando o processo é eficaz, o leitor atravessa três fases: (I) identificação com o personagem e projeção; (2) catarse (alívio emocional vivenciado ao revisitar emoções até então reprimidas) e, por fim, (3) insight e integração (ressignificação e motivação para 
eventuais mudanças) (Pardeck e Markward, I995: 76; Rozalski, Stewart e Miller, 2OıO: 34; Schlenther, I999: 30).

Para que ocorra a identificação, a história precisa ser cuidadosamente escolhida de forma que a criança consiga ver as semelhanças entre si mesma e o personagem do livro (Pardeck e Markward, I995: 75). Não por acaso, ensinar aos leitores, “[...] não pelo raciocínio, mas por meio de uma decifração inconsciente, que aquilo que os assusta pertence a todos" (Petit, 2009: 49) é uma das funções da literatura. No entanto, ainda mais importante do que a criança reconhecer a si mesmo como em um espelho é que ela se reconheça enquanto alguém que tem "um direito legítimo a ter um lugar, a ser aquilo que é, ou, mais ainda, a se converter naquilo que já sabia que era” (Petit, 200I: 48).

Embora a biblioterapia estritamente falando deva ser conduzida por profissionais adequadamente treinados (Lucas e Soares, 20I3: I39), qualquer cuidador que tenha uma forte relação com a criança pode ajudá-la a utilizar livros de uma forma terapêutica no dia a dia (Schlenther, I999: 29 e 3I), ainda que lhes falte treinamento em psicologia, já que a terapia pela leitura envolve a relação entre o leitor e o conteúdo do livro e, embora possa ser ajudada por um facilitador, não depende deste (Forrest, I998: 158).

Seja sob a forma de sessões estruturadas de biblioterapia propriamente dita, seja de uma maneira menos formal e em caráter eventual, muitos psicólogos e psiquiatras utilizam livros no setting terapêutico. Alguns fazem isso apenas deixando-os à disposição (dentro do consultório ou mesmo na sala de espera) e observando o eventual interesse da criança por determinado título. Outros vão além e usam os livros ativamente, seja selecionando títulos para ler com a criança, seja sugerindo determinada leitura em casa (com ou sem os pais, dependendo do caso e da idade do paciente). Tais diferenças refletem não apenas preferências pessoais do profissional, mas, muitas vezes, a linha terapêutica seguida por ele.

\section{Objetivos}

Procurou-se, neste trabalho, conhecer a opinião de alguns profissionais de saúde mental sobre a utilidade de livros infantis para ajudar crianças a lidarem com questões emocionais suscitadas pela migração, além de perceber que assuntos eles esperariam ver abordados em livros do gênero. A seguir, procuramos analisar se e de que formas as questões apontadas se fazem presentes no livro Pássaro que voa.

\section{Metodologia}

Foi realizada uma investigação qualitativa com um pequeno grupo de psicólogos $(n=23)$ e psiquiatras infantis $(n=2)$ que responderam a um convite (através de postagem em rede social) para compartilhar suas impressões sobre o uso da literatura para ajudar 
crianças migrantes no processo de adaptação. Um questionário online semiestruturado contendo I5 perguntas foi enviado a todos que aceitaram participar.

A seguir, procedeu-se a uma pesquisa sobre livros infantojuvenis com esta temática que obedecessem a dois critérios: (I) tivessem sido publicados em Portugal nos últimos dois anos, isto é, entre 20I7 e 20I9 e (2) estivessem disponíveis na rede de bibliotecas municipais de Aveiro (que inclui as bibliotecas escolares). Restringimos a escolha da obra analisada àquelas disponíveis na rede municipal de bibliotecas para garantir que o livro selecionado fosse de acesso fácil, livre e gratuito ao público geral. Apenas um livro se enquadrou nos critérios: Pássaro que voa, de Claudio Hochman, o qual foi analisado à luz das respostas dos profissionais de saúde mental.

\section{Resultados}

Obtiveram-se, no total, as impressões de 23 profissionais (dois psiquiatras infantis e 2I psicólogos), a maioria dos quais ( $\mathrm{n}=\mathrm{I} 6$ ) com mais de dez anos de atuação na área. A grande maioria já usou livros como ferramentas terapêuticas no atendimento a seus pacientes, tanto adultos (2O entre os 23 entrevistados) como crianças (entre os I7 profissionais que atendem crianças, apenas um nunca recomendou ou utilizou livros no atendimento infantil). A forma de utilização dos livros, entretanto, variou conforme a idade dos pacientes. Para os adultos, os profissionais costumam sugerir a leitura de determinado(s) título(s) em casa, enquanto que, atendendo crianças, o livro é mais comumente lido em conjunto (profissional e criança) no próprio consultório.

Alguns entrevistados $(n=5)$ já atenderam crianças que vieram para tratamento por causa de uma questão provocada pela migração, enquanto outros $(n=2)$ atenderam casos em que, embora as dificuldades relacionadas à migração não tenham motivado diretamente a busca por tratamento, estavam presentes de forma muito significativa complicando o quadro. Este fato ilustra o quão desafiador o processo de migrar pode ser para os mais jovens. Segundo os entrevistados, os problemas mais comuns trazidos por estas crianças foram sensação de distanciamento da sua cultura e dificuldade de adaptação à nova, dificuldade em se expressar e em acompanhar aulas no novo idioma (com consequentes repercussões no rendimento escolar) e dificuldade de socialização (exclusão da criança dos grupos sociais, rejeição, preconceito e isolamento). Outras questões citadas foram sensação de não pertencimento, dificuldade em fazer novas amizades, saudades de amigos e familiares, dificuldade de adaptação ao clima e dificuldades financeiras.

A quase totalidade dos entrevistados $(n=22)$ acredita que livros onde o personagem principal vive problemas parecidos com os da criança podem ajudá-la a lidar com estas questões, uma vez que perceber que não é a única a viver aquela situação traz um senso de normalidade e, consequentemente, de algum pertencimento, reduzindo o isolamento e a solidão. Além disso, fica mais fácil explicitar angústias e fantasias, nomear medos e, conhecendo novas formas de lidar com as experiências vividas, pensar em novas saídas e soluções. 
A maior parte dos entrevistados $(\mathrm{n}=\mathrm{I} 8)$ recomenda/ $\mathrm{usa}$ livros de literatura (embora destes, 6 também recomendem/usem livros de autoajuda e psicoeducação). Apenas dois participantes recomendam/usam exclusivamente livros de autoajuda.

Questionados sobre quais pontos consideram importantes em um livro que aborde a questão das migrações, o respeito às diferenças foi citado por quase todos, bem como as questões identitárias, já que a criança deve ser capaz de se adaptar a uma nova cultura sem que, para isso, precise “matar” suas raízes. Muitos pontuaram que esta questão pode ser confusa para a criança, a qual, muitas vezes, entende que precisa "apagar" sua vida anterior para ser aceita no novo ambiente, o que traz tristeza, conflito e culpa. Por fim, eles ressaltaram que seria importante abordar e validar os sentimentos de perda, saudade, medo e luto mas, ao mesmo tempo, estimular a autoaceitação, a recepção do novo e a esperança.

Pássaro que voa. Pesquisando as principais plataformas de vendas de livros, sites de editoras e livrarias portuguesas, foram encontrados sete livros abordando a temática da migração publicados entre 20I7 e 20I9 por editoras portuguesas: O barco das crianças, de Mario Vargas Llosa; Querido Mundo: a história de uma menina síria vítima da guerra, de Bana Alabed; O lápis mágico de Malala, de Malala Yousafzai (todos da editora Presença); Refugiados e migrantes, de Ceri Roberts (Bertrand); Os meus irmãos refugiados, de Thereza Ameal (Paulus); A viagem, de Francesa Sanna (Fábula) e Pássaro que voa, de Claudio Hochman (Livros Horizonte). A seguir, realizou-se uma busca no catálogo da rede de bibliotecas municipais de Aveiro, sendo Pássaro que voa o único título disponível dentre os sete.

Pássaro que voa reúne 50 pequenas histórias (reais e fictícias) que falam sobre migração. Alguns dos personagens aparecem mais de uma vez durante o livro, que se divide em duas partes: a primeira chama-se Desencontros e contém 25 personagens diferentes (adultos e crianças de ambos os sexos) que contam um pouco sobre si e suas experiências. Os relatos são sempre na primeira pessoa, facilitando o processo de identificação do leitor.

Na segunda metade do livro, os personagens apresentados em Desencontros voltam a aparecer mas, desta vez, suas vidas vão se encontrando (e, mais do que isso, se enredando). Esta metade, não à toa, chama-se Encontros e, nela, são raros os personagens novos adicionados.

Para exemplificar como as histórias se entrelaçam ao longo do livro, temos a história de Aaliyah, uma menina chinesa privada de algo tão básico para seu senso de identidade como o próprio nome. Ninguém o pronuncia corretamente no país em que está, chamam-na por outros nomes. Pouco à frente, conhecemos Maria, outra criança chinesa que, entretanto, foi adotada por estrangeiros pois seus pais não puderam ficar com ela pelas questões de controle de natalidade (e gênero) em seu país de origem e Sérgio, um menino de Costa Rica que teme pela vida do pai, um soldado enviado para o Afeganistão (este também personagem do livro). Na segunda parte da obra, Encontros, estas três personagens infantis (Aaliyah, Maria e Sérgio) se encontram na escola, onde uma quinta 
personagem, Emília, é professora. Aaliyah e Maria se identificam uma com a outra (“Temos feições parecidas. Sobretudo os olhos”) (Hochman, 20I7: 86) e desenvolvem, a partir daí, uma amizade que alivia o senso de não pertencimento, acolhe e até permite que Maria aprenda a língua de sua terra natal, que seus pais adotivos não conhecem e, portanto, não podem transmitir.

Sérgio, que vê o medo de perder o pai virar realidade, acaba por encontrar, neste ambiente escolar, um espaço de acolhimento e solidariedade que o ajuda a lidar com o luto. A opção por um universo próximo à criança (a escola) como cenário para o encontro destes cinco personagens tende a facilitar o reconhecimento e a identificação por parte do leitor (Ramos, 20I6: 37).

Nem todos os encontros em Pássaro que voa, no entanto, são livres de conflitos ou têm final feliz. Nadia, por exemplo, traz uma história triste desde o início: é uma engenheira ucraniana que precisou deixar seu país e, consequentemente, filho e mãe, em busca de trabalho. Seu relato não explicita qual o país de destino, mas, nele, sabemos que "não aceitam" seu diploma de engenheira, e ela passa a limpar casas, o que afeta tanto seu senso de identidade que ela chega a sentir-se um nada: "Olá, chamo-me Nadia. Nadia, não Nada. Embora aqui me sinta um pouco dona Nada” (Hochman, 2OI7: IO). Nadia interage com uma personagem que, apesar de ser ela mesma estrangeira, não gosta de estrangeiros: a tentativa de se estabelecer no novo país fracassa e termina com Nadia retornando para a Ucrânia.

A xenofobia é abordada ainda mais duramente através da história de Pedro, um jogador de futebol profissional, que, na primeira metade do livro, nos conta um episódio bastante revelador: quando era criança, seu pai o levou ao estádio pela primeira vez. Seu time venceu o adversário, da Holanda. Durante as comemorações da vitória, Pedro relembra:

queimaram uma bandeira daquele país. Enquanto ardia, um sorriso iluminava a cara do meu pai. Nesse dia ele deixou-me beber uma cerveja pela primeira vez. Tinha sabor a vitória. Desde esse dia, odeio os holandeses. Não me perguntem porquê. Se nos tivessem ganho, perceberia o ódio. Mas não. Não sei porquê. Na realidade, odeio todos os que não são daqui (Hochman, 2OI7: I2).

Este episódio traz implícita a ideia da responsabilidade dos pais na modelação de sentimentos de intolerância para seus filhos através do exemplo. O pai de Pedro não precisou verbalizar seus sentimentos negativos contra os estrangeiros: bastou Pedro observar seus comportamentos e a expressão de suas emoções para não só perceber como "copiar" essa intolerância.

Já na parte dos Encontros, o caminho de Pedro cruza com os de mais dois personagens: José, um jogador de futebol brasileiro, e Amir, um vendedor africano. Pedro vive em um estado de ânimo raivoso e frustrado, odeia o vizinho africano que fala alto demais 
e dá festas nas quais o cheiro da comida se espalha pelo prédio:

Antes de cá entrarem deveriam-lhes fazer um exame de cidadania, de moral e de bons costumes. E de cultura. Deveriam exigir-lhes que saibam cozinhar as nossas comidas, que respeitem os nossos hábitos, que celebrem os nossos feriados, que acreditem no nosso Deus (Hochman, 20I7: 64).

Odeia também o colega brasileiro, "ele que seguramente não paga os impostos, que dorme com as nossas mulheres e as despreza, que se ri em segredo dos nossos costumes" (Hochman, 20I7: 74). Os encontros entre estes três personagens é altamente conflituoso: enquanto Pedro chega a furar os pneus de Amir, o ódio pelo brasileiro, que ele vê como rival, vai além: "A este, mato-o, e estou mesmo a falar a sério. Porque uma coisa é incomodar-me a mim, outra coisa muito mais grave é humilhar o meu país e a sua ilustre história" (Hochman: 74).

Albert Einstein também está presente no livro e sua genialidade não o impede de ser vítima do ódio racial. Quando Hitler sobe ao poder, ele abandona seu continente e sua nacionalidade de uma só vez para fugir da xenofobia aflorada pelo nazismo.

Manuel, por sua vez, é o personagem que talvez melhor expresse o lado triste do choque cultural. Sendo um homem divertido, que gosta de contar piadas e brincar com os múltiplos sentidos das palavras, sente que perdeu o sentido do humor, pois, no país em que está, as pessoas riem-se de outras coisas e não acham graça às suas piadas. Este personagem, na tentativa de adaptar-se, sacrifica o senso de humor que lhe é tão caro e parte tão significativa de sua personalidade. Na ilustração que acompanha o texto, o vemos afastado do grupo, observando, de longe, três amigos rirem e conversarem, enquanto nos diz: "Aqui, calo-me, observo. Agachado num canto, vejo como a vida passa num país onde o meu humor não tem espaço" (Hochman, 20I7: 22-23). A resignação de Manuel continua na segunda parte do livro, onde o vemos convencendo a esposa de que devem continuar ali, onde estão bem, onde têm um médico de família e, os filhos, uma boa escola: "É verdade que estamos sós, que nossos filhos não têm cá nem os avós, nem os tios, nem os primos ... mas nada disso importa. Estamos bem. Sem sentido de humor, sem sentido nenhum, mas estamos bem" (Hochman: IO2).

A saudade está presente na narrativa de diversos personagens. José, o jogador de futebol, sente saudades da mãe e gostaria de trazê-la para morar com ele; Albert (Einstein) sente enormes saudades da irmã; Amir sente falta do mar; Nadia, do filho; Noralia expressa, em uma carta aos pais, a saudade e o estranhamento do clima em uma só frase: "Na Finlândia está frio. Muito frio. Na Finlândia sente-se saudades como em nenhum outro lugar do mundo" (Hochman, 2OI7: 48).

O medo, por sua vez, também é explicitado por vários personagens. Aisha, uma pequena sudanesa, pula corda em um campo para refugiados, a fim de se esquecer da fome, da sede e do medo das explosões; Miguel é a prova de que os adultos (e mesmo os 
adultos soldados) também têm medo (“Tenho medo, mas isso é segredo. Soldados não podem ter medo") (Hochman, 2OI7: 52); Sérgio, filho de Miguel, tem medo de que o pai morra. E, de fato, no decorrer da narrativa, os piores medos de alguns personagens efetivamente se concretizam: Aisha morre em um bombardeio e Miguel, pai de Sérgio, morre na guerra. A tristeza do avô de Aisha é ilustrada pela sua imagem olhando a fotografia da neta; Sérgio encontra, na escola, um espaço de acolhimento, solidariedade e compreensão onde poderá elaborar seu luto.

Em suma, a grande maioria dos problemas apontados pelos entrevistados foi explorada ao longo das páginas de Pássaro que voa, nomeadamente as questões identitárias, o respeito (ou, por outro lado, a intolerância) às diferenças, os sentimentos de exclusão social, perdas, saudades, medos, luto e esperança.

\section{Discussão}

Observamos que a quase totalidade dos tópicos que os profissionais entrevistados apontaram como relevantes para a criança migrante são abordados no livro, razão pela qual acreditamos que ele pode ser considerado como uma das opções disponíveis para trabalhar questões disruptivas relacionadas à migração. No entanto, cabem algumas observações.

Em primeiro lugar, o livro não traz uma história única, mas uma série de relatos, apenas alguns dos quais se entrelaçam. Embora idealmente (quando pensamos em terapia pela leitura) histórias longas e complexas devam ser evitadas (Lucas e Soares, 20I3: I42), os relatos em Pássaro que voa são excessivamente curtos (cerca de uma página cada) e, consequentemente, os personagens não são suficientemente aprofundados, $o$ que poderia dificultar o processo de identificação. Por outro lado, a grande diversidade de histórias fornece um amplo leque para que o leitor encontre aquele personagem (ou personagens) com os quais mais se identifica, e o trabalho terapêutico pode perfeitamente focar apenas nestes, sem necessidade de se ler o livro todo. Além disso, há um ponto interessante em mostrar uma grande diversidade de personagens: a percepção de que pessoas tão diferentes estão unidas por dificuldades relacionadas ao mesmo estressor pode atenuar a sensação de isolamento, inserindo o drama pessoal de cada um em um contexto mais amplo. A opção por mesclar personagens reais e fictícios também é interessante já que, como explica Berg (et al., r980: 43), "livros que as crianças sentem ser sobre pessoas reais em situações reais são infinitamente preferíveis".

Como já discutido, a literatura "fora de perigo" - que não toca nas grandes questões existenciais e nos grandes medos - não consegue ajudar verdadeiramente as crianças. Isso pode ser um problema porque muitos pais, na ânsia de proteger os filhos de todo e qualquer desconforto, acreditam que devem mantê-los afastados dos assuntos que consideram tristes e difíceis. Não é incomum na prática clínica encontrar pais assim que, tentando (inutilmente) manter a criança isolada em um mundo "cor-de-rosa", perdem 
excelentes oportunidades de ajudá-la a crescer e acreditar na própria capacidade de lidar com as dores. O livro de Hochman não procura amenizar a realidade como estes pais esperariam em um livro infantojuvenil. Pelo contrário: fala abertamente sobre questões extremamente estressantes para crianças (não só as migrantes), como a morte dos pais, $o$ abandono, a exclusão social e mesmo a própria morte. Ao optar por explorar estes medos em lugar de negá-los, o livro valida-os, oferecendo aos leitores não apenas a chance de refletir e dialogar sobre eles, mas mostrando-lhes que são comuns, são sentidos por todos, são normais.

Algumas das histórias trazidas pelo livro, no entanto, são verdadeiramente perturbadoras - como a de Aisha (a pequena sudanesa morta no bombardeio). Uma criança migrante/refugiada que tenha enfrentado problemas semelhantes, ou que, por exemplo, ainda tenha familiares em risco no país de origem, pode estar fragilizada e amedrontada demais para conseguir, naquele momento, se debruçar sobre uma história como essa. Sendo assim, nunca é demais lembrar que o mediador, quando existente, deve ser alguém com bom senso e sensibilidade suficientes para entender que duas crianças vivenciando o mesmo problema podem precisar de abordagens distintas e ter timings diferentes. Por exemplo: enquanto uma criança gravemente enferma, como exemplificado por Petit (200I: 49) pode pedir repetidamente pela história de um animalzinho que morre, outra na mesma situação pode se sentir assoberbada com histórias similares (Berg et al., I980: 44). Desta forma, a eventual recusa da criança em ler determinado livro deve sempre ser respeitada (Berg et al.: 43).

Apesar de indicado "para todas as idades" no site da editora Livros Horizonte, acreditamos que o livro seja mais indicado para crianças a partir dos dez ou doze anos e adolescentes. Embora as histórias sejam formadas por frases relativamente simples e curtas, permitindo o entendimento por crianças em idade escolar, ao nível do $\mathrm{I}^{\mathrm{o}}$ Ciclo do Ensino Básico, outros aspectos do livro, como os elementos intertextuais envolvendo textos complexos como As babas do diabo, de Julio Cortázar e obras de Ernest Hemingway (O velho e o mar, Paris é uma festa, O sol também se levanta, e Por quem os sinos dobram) serão melhor percebidos por crianças mais velhas e adolescentes. Mesmo estas narrativas, entretanto, ainda podem ser aproveitadas por leitores que não percebam a intertextualidade - como é verdade para quase todo texto, inúmeras leituras são possíveis e cada um fará a sua de acordo com seu próprio conhecimento. Além disso, há uma quantidade significativa de personagens adultos protagonizando os relatos - o que favorece a identificação pelos leitores mais velhos, já que as crianças tendem a se interessar mais por histórias envolvendo personagens com idades próximas às suas.

Uma particularidade interessante é o fato de o próprio autor da obra, Claudio Hochman, ser imigrante. Já que escrever pode ser um exercício catártico que ajuda a lidar com memórias dolorosas, é possível explorar este aspecto nas atividades e reflexões pós-leitura. Além de discutir o que pode ter motivado Hochman (um argentino que se mudou para Portugal) a escrever o livro, outras possibilidades interessantes incluem estimular as crianças a escreverem suas próprias experiências (boas ou más) associadas à migração, 
criar poesias ou escrever cartas para parentes e amigos que ficaram no país de origem. Como ressalta Valle (2002: 6o9), "para crianças que passaram por experiências migratórias, a escrita expressiva pode auxiliar o processo de cura e promover o desenvolvimento pessoal”.

As ilustrações do livro foram feitas por uma artista que tinha, à época, II anos de idade. Esta opção por desenhos onde se percebem traços infantis pode favorecer a identificação por parte das crianças e, ainda, incentivar atividades pós-leitura como, por exemplo, que os leitores, à semelhança da desenhista, criem suas próprias ilustrações - estratégia interessante para estimular a autoexpressão, ultrapassar barreiras de linguagem e resistências e ajudar a criança a externalizar seus sentimentos e memórias de forma mais leve (Valle, 2002: 6o9). Por outro lado, o grafismo do livro não é explorado da mesma forma que a contratação de um desenhista ou designer permitiria, e o caráter estático, pouco detalhado e tímido no uso das cores pode tornar as ilustrações menos atrativas visualmente (especialmente para crianças mais novas).

Embora a biblioterapia seja uma forma de terapia exercida por profissionais treinados seguindo protocolos mais ou menos rígidos, não é necessário o emprego formal de um protocolo de biblioterapia para que se extraia um valor terapêutico de determinados livros. A um certo nível, qualquer adulto cuidador pode fazer terapia de leitura com crianças (Schlenther, I999: 29) sendo a qualidade do rapport entre criança e mediador um dos principais requisitos para que a história tenha poder terapêutico (Pardeck, I99O: IO45; Webster, I96r: I6I).

Neste sentido, os pais, com seu conhecimento único sobre a criança, estão em posição privilegiada para ajudá-la na terapia pela leitura. Entretanto, é importante lembrar que, em alguns casos, os pais, eles próprios migrantes, também estão experimentando um significativo nível de estresse e que a tendência das crianças a se adaptarem mais rapidamente pode gerar conflitos intergeracionais (Valle, 2002: 6o4). Por outro lado, a leitura pode proporcionar aos pais um maior insight acerca dos problemas vivenciados tanto pelos filhos como por eles mesmos (Berg et al., I980: 45; Pardeck e Markward, I995: 80), gerando efeitos terapêuticos para ambos.

Fora da esfera individual, a leitura de histórias sobre migrantes também tem um papel social. Lidas na sala de aula ou em pequenos grupos, por exemplo, podem suscitar importantes reflexões e discussões, especialmente se impulsionadas por um mediador sensível e capacitado. Nestes casos, a figura do mediador é tão relevante porque, como explica Morgado (2OIO: I5), mais importante do que ler é refletir sobre como ler, pois só a leitura crítica, que envolve refletir e dialogar, contribui para a transformação da sociedade. A reflexão e o diálogo não devem se limitar ao conteúdo do livro, mas se estender à forma como os textos funcionam e se relacionam com o mundo, enfatizando-se menos a sua compreensão do que a competência para questioná-los (Morgado: I5). O ato de ler, segundo a autora,

deve ser sinónimo de desocultar ideologias dominantes, integrar a sua própria 
experiência social com a leitura de modo a traduzi-la em acção social, [...] descascar o texto como se tratasse de uma cebola e ir tomando consciência das decisões de autores, ilustradores, das suas inclusões e omissões (Morgado, 20IO: I5).

Esta é uma questão pertinente porque a migração afeta a todos (não apenas aos que migram) e a adaptação das crianças à nova comunidade não é tarefa única da família ou da escola, mas de toda a sociedade que se pretenda intercultural. Uma sociedade verdadeiramente intercultural - em que os diferentes grupos multiculturais, muito mais do que apenas conviverem pacificamente, integram-se genuinamente entre si (Morgado, 2OIO: 5) - é também uma sociedade mais empática. Livros infantis que abordem tais questões, portanto, não são importantes apenas para os próprios imigrantes/refugiados, mas ajudam as crianças que estão em seu país de origem a compreenderem melhor (e se responsabilizarem por) aquilo que se passa com seus pares.

\section{Considerações finais}

A migração implica em um processo de luto e exige uma adaptação a um ambiente completamente novo, tarefas cuja responsabilidade não se limita à criança migrante e seu microambiente, mas se estende à sociedade que a acolheu. O livro Pássaro que voa reúne uma série de histórias que podem ajudar na elaboração deste processo, na medida em que validam sentimentos de não pertencimento, perda, saudade e medo, promovendo, simultaneamente, a autoaceitação, a recepção do novo e a esperança. Certamente existirão outros livros sobre migração igualmente úteis para trabalhar estas questões disruptivas - e mesmo um sem número de livros com outros temas que não a migração. Inúmeras narrativas começam com um herói ou heroína partindo de casa e forjando sua identidade a partir deste desenraizamento (Petit, 2OOI: 45): virtualmente todas elas serão, por si só, "desterritorializantes" e capazes de ajudar o leitor a criar novos espaços de pertencimento (Petit, 2OOI: 44).

Por fim, uma vez que o ideal na leitura terapêutica é deixar a criança escolher entre diversas opções (Schlenther,r999: 32), gostaríamos de ter encontrado mais títulos semelhantes na rede municipal de bibliotecas da área onde se realizou o estudo. 


\section{Referèncias Bibliográficas}

- Agência da ONU para refugiados. (2OI7). Acessado em 25 de fevereiro de 2020 em https://www.acnur.org/.

- Balça, A. (2008). Literatura infantil portuguesa: De temas emergentes a temas consolidados. E-fabulations: e-journal of children's literature, 2, 24-32. Acessado em 25 de fevereiro de 2020 em https://ler.letras.up.pt/uploads/ficheiros/ 4668.pdf.

- Berg, P.J.; Devlin, M.K. e Gedaly-Duff, V. (I980). Bibliotherapy with children experiencing loss. Issues in Comprehensive Pediatric Nursing, 4, 37-50. Acessado em Io de março de 2020 em https://www.tandfonline.com/doi/abs/IO.3IO9/OI460868009O24I96.

- Bettelheim, B. (2002). A psicanálise dos contos de fadas. São Paulo: Paz e Terra.

- Candy, J. e Butterworth, D. (1998). Through young children's eyes: The experience of migration to Australia. Australian journal of early childhood, 23(3), 20-25. Acessado em Io de março de 2020 em https://search.informit.com.au/documentSummary;d$\mathrm{n}=99030268$ i;res $=$ IELAPA.

- Estés, C. P. (I999). Mulheres que correm com os lobos: Mitos e histórias do arquétipo da mulher selvagem. Rio de Janeiro: Rocco.

- Forrest, M.E.S. (1998). Recent developments in reading therapy: A review of the literature. Health libraries review, I5, I57-I64. Acessado em Io de março de 2020 em https://onlinelibrary.wiley.com/doi/abs/IO.IO46/j.I365-2532.I998.I53OI57.X.

- Hochman, C. (20I7). Pássaro que voa. Lisboa: Livros Horizonte.

- Lindeman, B. e Kling, M. (I969). Bibliotherapy: Definitions, uses and studies. Journal of school psychology, 7(2), 36-41. Acessado em Io de março de 2020 em https://doi. org/Іо.Іог6/oо22-4405(68)9ог30-I.

- Lucas, C.V. e Soares, L. (20I3). Bibliotherapy: A tool to promote children’s psychological well-being. Journal of poetry therapy, 26(3), I37-I47. Acessado em I5 de março de $2020 \mathrm{em}$ https://doi.org/Io.Io8o/o8893675.20I3.823310.

- Morgado, M. M. (20I0). As diferenças que nos unem: Literatura infantil e interculturalidade. Álabe, o(I), I-2I. Acessado em 25 de fevereiro de 2020 em http://revistaalabe.com/ index/alabe/article/view/6/4.

- Pardeck, J.T. (1990). Using bibliotherapy in clinical practice with children. Psychological reports, 67, IO43-IO49. Acessado em I5 de março de $2020 \mathrm{em}$ https://journals.sagepub. com/doi/pdf/IO.2466/pro.I990.67.3.IO43. 
- Pardeck, J.T. e Markward, M.J. (I995). Bibliotherapy: Using books to help children deal with problems. Early child development and care, Io6(I), 75-90. Acessado em I5 de março de 2020 em https://doi.org/Io.Io8o/o30044395Io6oio8.

- Plataforma de apoio aos refugiados. (20I8). Acessado em 25 de fevereiro de $2020 \mathrm{em}$ http://www.refugiados.pt/a-par/.

- Petit, M. (200I). Lecturas: Del espacio íntimo al espacio público. Ciudad de México: Fondo del cultura economica.

- Petit, M. (2009). A arte de ler: Ou como resistir à adversidade. São Paulo: Editora 34.

- Ramos, A. M. (20I6). Tendências contemporâneas da literatura portuguesa para a infância e a juventude: Desafios atuais. Em E. Debus, D. B. Juliano e N. Bortolotto (Orgs.). Literatura infantil e juvenil do literário a outras manifestações estéticas (35-58). Santa Catarina: UDESC.

- Rapee, R.M.; Abbott, M.J. e Lyneham, H.J. (2006). Bibliotherapy for children with anxiety disorders using written materials for parents: A randomized controlled trial. Journal of consulting and clinical psychology, 74(3), 436-444. Acessado em Io de março de $2020 \mathrm{em}$ https://psycnet.apa.org/doiLanding?doi=IO.IO37\%2Foo22-Oo6X.74·3.436.

- Rozalski, M.; Stewart, A. e Miller, J. (20IO). Bibliotherapy: Helping children cope with life's challenges. Kappa delta pi record, 47 (I), 33-37. Acessado em I5 de março de $2020 \mathrm{em}$ https://doi.org/IO.IO80/oO228958.20IO.IO516558.

- Serviço de estrangeiros e fronteiras. (20I9). Relatório de imigração, fronteiras e asilo 2018. Acessado em 24 de fevereiro de 2020 em https://sefstat.sef.pt/Docs/Rifa2OI8.pdf.

- Schlenther, E. (I999). Using reading therapy with children. Health libraries review, I6, 29-37. Acessado em Io de março de 2020 em https://onlinelibrary.wiley.com/doi/ abs/IO.IO46/j.I365-2532.I999.OOI92.X.

- Valle, P. (2002). Traumatized refugee children. In S.E. Brock, P.J.Lazarus e S.R. Jimerson, Best practices in school crisis prevention and intervention (pp.599-614). Bethesda: NASP Publications.

- Webster, J. (I96I). Using books to rreduce the fears of first-grade children. The reading teacher, I4(3), I59-I62. Acessado em Io de março de 2020 em http://www.jstor.org/stable/20I97355. 